\title{
Eicosanoid Receptors and Their Role in Regulating Immune and Inflammatory Responses
}

\author{
Charles Brink \\ CNRS CR-1 PARIS, France \\ E-mail: charlesbrink@hotmail.com
}

Received July 9, 2007; Accepted July 9, 2007; Published September 1, 2007

There is an array of lipid mediators produced from arachidonic acid. These metabolic products derived from membrane phospholipids, by the actions of phospholipases, act by signaling through Gprotein coupled receptors. To better appreciate their impact and role during inflammation and the immune response, this issue of the TheScientificWorldJOURNAL brings into perspective our current biochemical knowledge of the eicosanoids, as well as information on their receptors and signaling pathways.

Since the hallmark of inflammation is a major perturbation in the vasculature, a considerable amount of information is reviewed dealing with blood cells and the vascular wall, as well as eicosanoid receptors and cellular signals observed in different animal models and human tissues. Although metabolites of the arachidonic acid cascade have often been documented to facilitate and enhance the inflammatory response, there are several metabolites that may markedly alter the intensity and duration of the reaction, thereby dampening this complex response. A considerable interest has arisen, therefore, to explore not only the proinflammatory, but also anti-inflammatory, eicosanoid actions during different phases of the inflammatory reaction.

While the eicosanoids and their receptors cooperate with many other molecules during the various phases of the inflammatory reaction, an attempt has been made to highlight the capacity of the eicosanoids to signal in the immune system by addressing their role in the "cross-talk" between disparate cell types during the immune response.

The papers presented in this issue hopefully will provide the reader with a summary of the eicosanoid receptor diversity and their association with both inflammation and the immune response. 

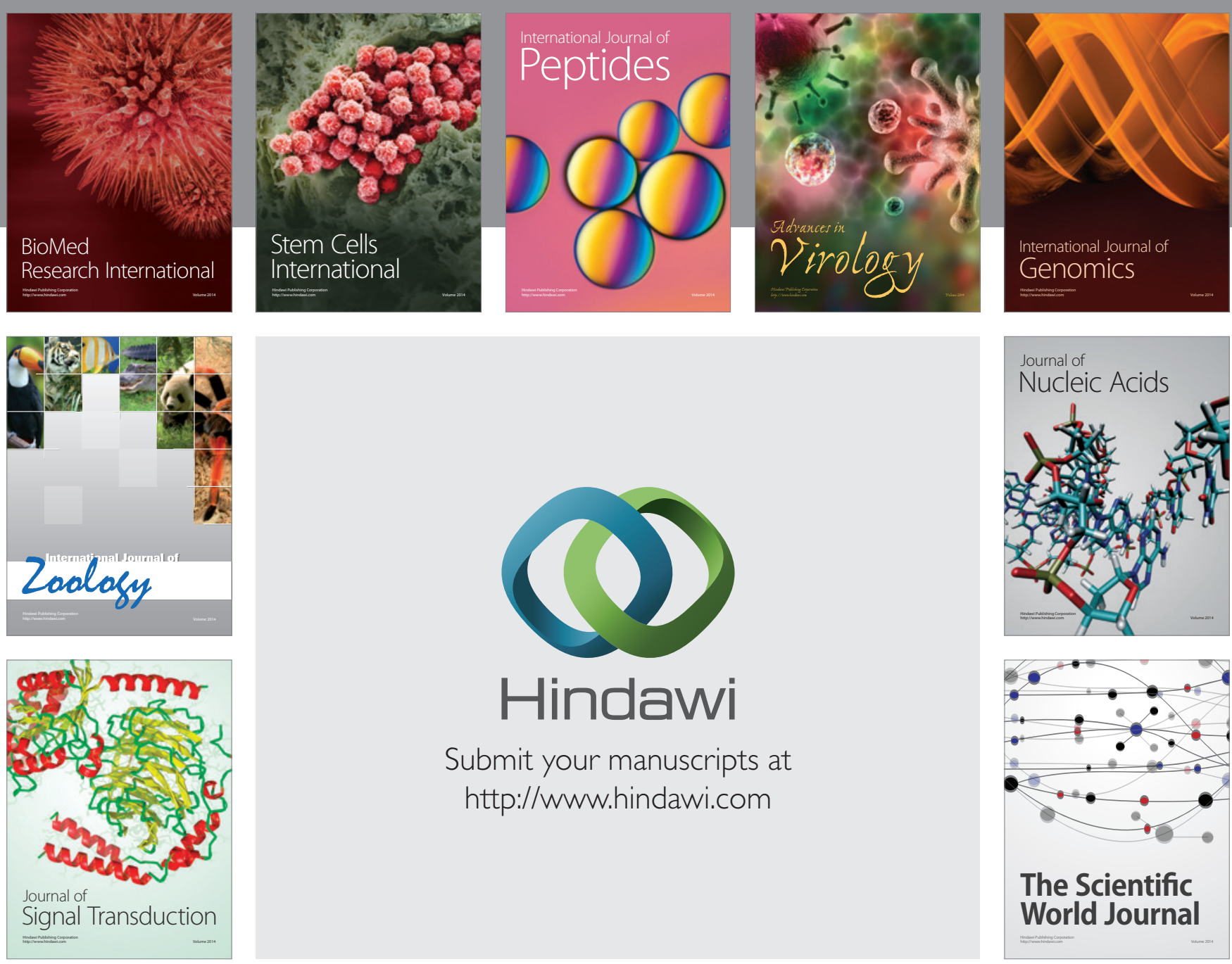

Submit your manuscripts at

http://www.hindawi.com
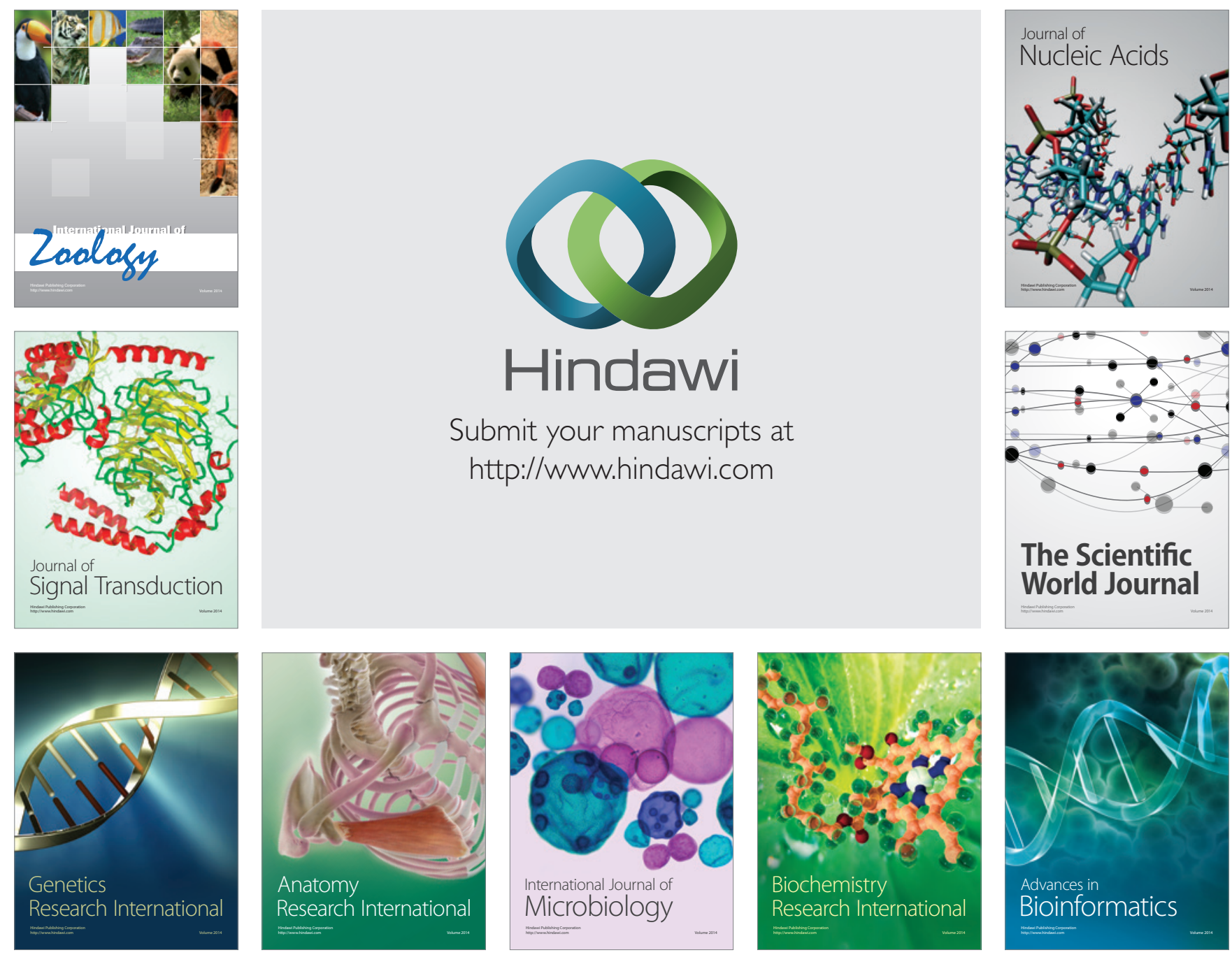

The Scientific World Journal
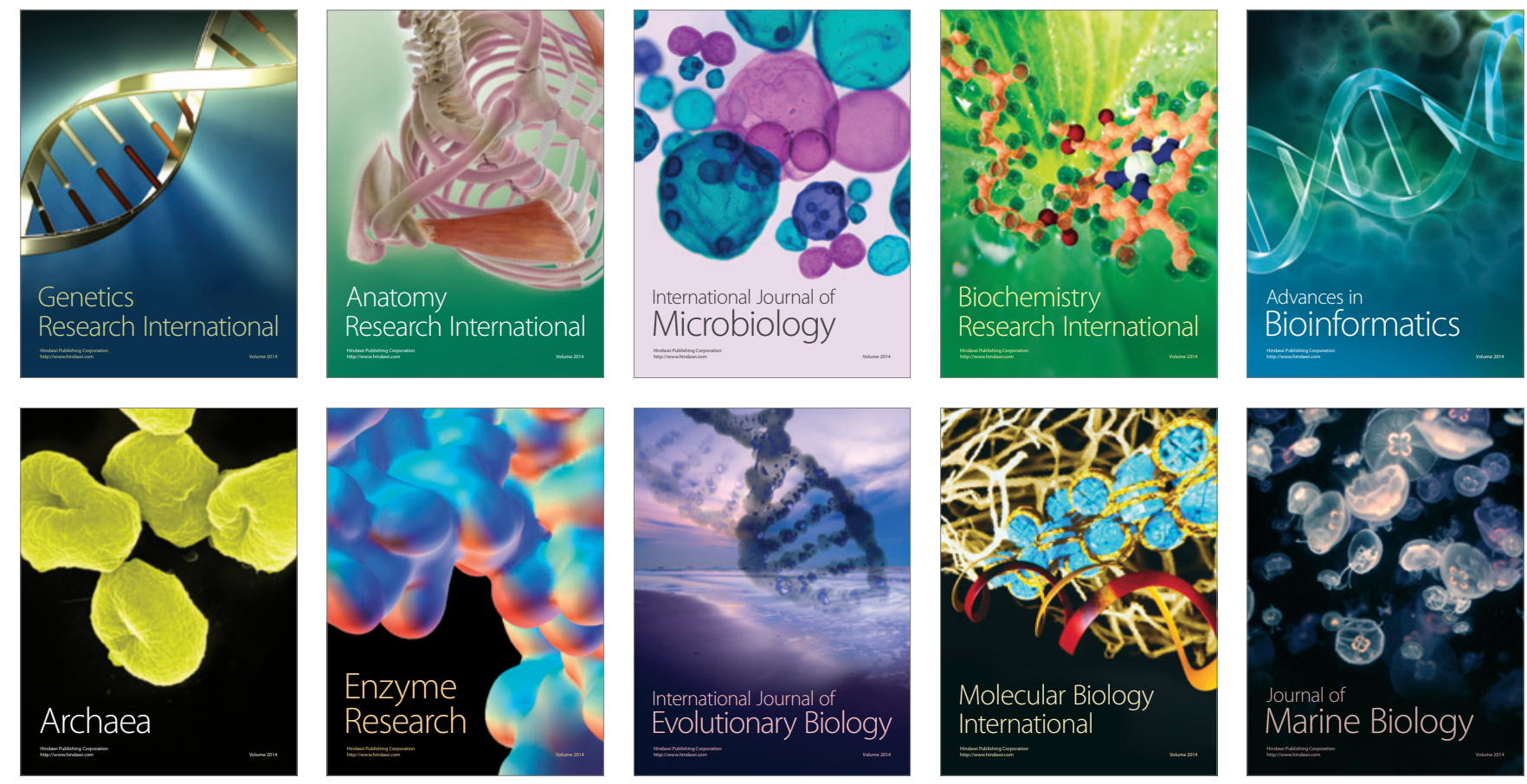